\title{
Dual-Beam, Charged-Particle Irradiation Facility for Simulation of Nuclear Environment
}

February 1978

Pacific Northwest Laboratory

Richland, Washington 99352

Operated for the

U.S. Department of Energy

by 


\title{
NOTICE
}

This report was prepared as an account of work sponsored by the United States Covernment. Neither the United States nor the Department of Energy, nor any of their employees, nor any of their contractors. subcontractors, or their employees, makes any warranty, express or implied, or assumes any legal liability or responsibility for the accuracy, completeness or usefulness of any information, apparatus, product or process disclosed, or represents that its use would not infringe privately owned rights.

The views, opinions and conclusions contained in this report are those of the contractor and do not necessarily represent those of the United States Government or the United States Department of Energy.

\author{
PACIFIC NORTHWEST LABORATORY \\ operated by \\ BATTELLE \\ for the \\ UNITED STATES DEPARTMENT OF ENERGY \\ Under Contract EY-76-C-06-1830
}
Printed in the United States of America Avallable from
National Technical information Service United States Department of Commerce
5285 Port Royal Road
Springtield, Virginia 22151

Price: Printed Copy S_: Microtiche $\$ 3.00$

-Pages NTI5

-Pages Selling Price

$001-025 \quad 54.50$

$026-050=55.00$

$051-075 \quad 55.50$

$076-100 \quad 56,00$

$101-125=56.50$

$126-150 \quad 570$

$151-175 \quad-5775$

$176-200 \quad 58.50$

$201-225 \quad \cdot \quad 5875$

$226-250 \quad 59.00$

$251-205 \quad 510.00$

$276-300 \quad 510.25$ 
DUAL-BEAM, CHARGED-PARTICLE IRRADIATION FACILITY

FOR SIMULATION OF NUCLEAR ENVIRONMENT

\author{
by \\ H. E. Kissinger \\ J. L. Brimha11 \\ E. P. Simonen \\ L. A. Charlot
}

February 1978

BATTELLE

Pacific Northwest Laboratories

Richland, Washington 99352 


\section{CONTENTS}

LIST OF FIGURES

LIST OF TABLES.

\section{SUMMARY}

INTRODUCTION

DUAL-BEAM FACILITY

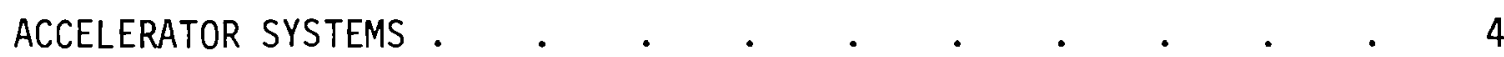

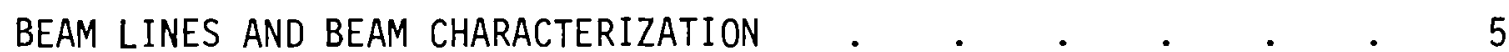

BOMBARDMENT CHAMBER . . . . . . . . . . . . . . . . 10

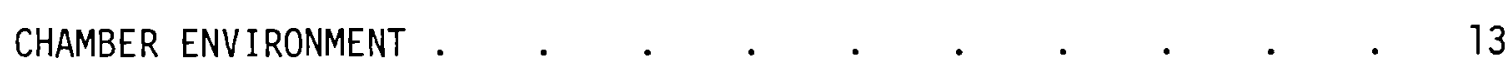

TEMPERATURE MEASUREMENT AND CONTROL $\quad . \quad \ldots \quad . \quad . \quad . \quad . \quad$. 14

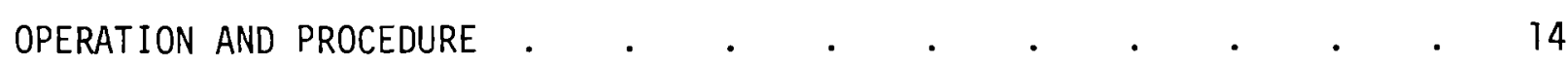

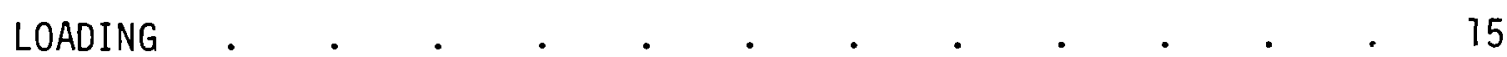

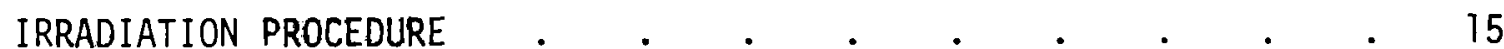

EXPERIMENTAL RECORDS $. \quad . \quad . \quad . \quad . \quad . \quad . \quad . \quad . \quad . \quad . \quad 17$

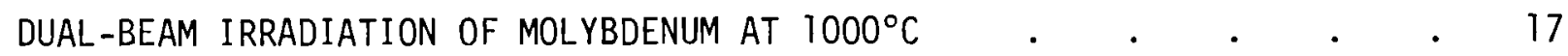

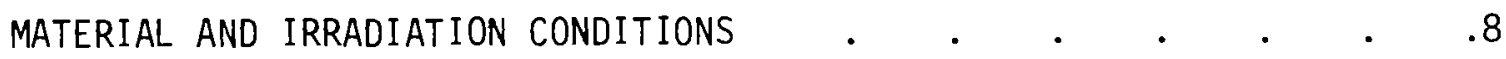

POST-IRRADIATION EXAMINATION

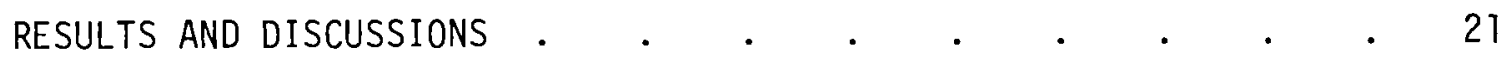

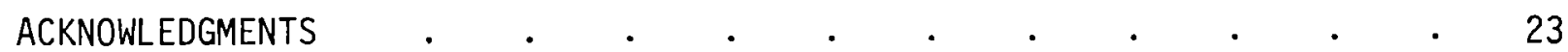

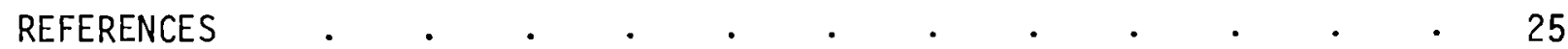

DISTRIBUTION 


\section{FIGURES}

1 Arrangement of the PNL Accelerator Laboratory a $\quad$. $\quad$. $\quad$. 6

2 Sample Chamber, Beam Lines, and Beam Handling Equipment

for Dual-Beam Irradiations . . . . . . . . . . 6

\begin{tabular}{l} 
Multichannel Analyzer Displays of $\mathrm{He}^{+}$Beam Energies Showing \\
Effect of Degrader Foil \\
\hline
\end{tabular}

4 Calculated Energy Distributions Compared with Multichannel

Analyzer Outputs for the Foil Normal to the Beam

and Tilted $30^{\circ}$.

5 Sample Chamber and Carrousel with Detail of Sample Mounting . $\quad 11$

6 Construction of the Individual Sample Heaters a . . . $\quad$ - 12

7 Damage Curve for $5-\mathrm{MeV} \mathrm{Ni}^{++}$Ions on Molybdenum and Distribution of Deposited $\mathrm{Ni}^{++}$Ions . $. \quad . \quad . \quad . \quad . \quad . \quad . \quad 19$

8 Distribution of Deposited Helium in Molybdenum for a Degrader of

Thickness $5 \pm 0.5 \mathrm{\mu m}$. $\quad . \quad$. $\quad . \quad$. $\quad . \quad 20$

9 Comparison of Microstructure in Molybdenum Irradiated to

2.0 dpa, with Simultaneous Helium Injection (Left) and

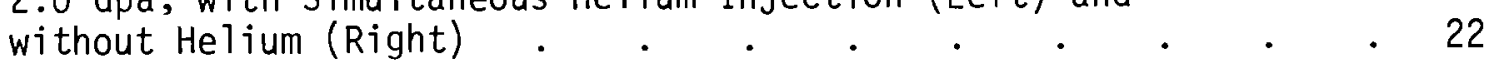

\section{TABLES}

1 Microstructural Parameters in Molybdenum Bombarded with

$5-\mathrm{MeV} \mathrm{Ni}{ }^{++}$and $200-\mathrm{keV} \mathrm{He}^{+}$Ions . . . . . . 23 


\section{SUMMARY}

Heavy-ion bombardment provides a method for simulating neutron damage to metals and other materials. Simultaneous implantation of $\mathrm{He}^{+}$ions allows the study of effects of neutronically generated helium in these samples. A 2-MeV Van de Graaff and a 2-MeV tandem accelerator at Battelle, Pacific Northwest Laboratories (PNL) have been combined to provide dual-beam irradiation with heavy ions, $\mathrm{Ni}^{++}$or $\mathrm{Ta}^{++}$, and with $\mathrm{He}^{+}$ions .

This irradiation facility allows independent control of beam currents and energies for both heavy-ion and helium-ion beams, as well as sample temperatures to $1200^{\circ} \mathrm{C}$. It will be used both for investigation of materials for advanced reactor applications and for basic studies of radiation damage mechanisms.

Preliminary results on molybdenum irradiated to two dose levels at $1000^{\circ} \mathrm{C}$, with and without simultaneous helium implantation, show the effect of helium on void nucleation. When helium is continuously implanted, the number of voids increases with dose. Without helium, existing voids grow in size but the number is unchanged. At higher heavy-ion dose rates, this effect of helium is less pronounced. 


\section{INTRODUCTION}

Advances in nuclear reactor designs are usually accompanied by requirements for materials to operate longer, at higher temperatures, and in a higher flux than any preceding system. As a result, materials scientists are constantly working to characterize and evaluate the behavior of reactor structural materials in these extreme environments. Obviously, foreknowledge of potential materials shortcomings is vitally important to reactor designers, and the earlier this information is available the better. Postirradiation examination, while useful and necessary, provides only after-the-fact information. All too often costly and time-consuming delays have been caused by belated recognition of unsuspected materials problems.

Heavy-ion bombardment provides a way to compress the time scale necessary for accumulating irradiation damage data. This method uses the fact that the elastic-scattering cross section for heavy ions is several orders of magnitude larger than for neutrons. A given number of atomic displacements can thus be made to occur in a much shorter time. The heavy-ion method has been used extensively in the last few years, both to simulate neutron damage and thereby predict behavior in an actual reactor environment $(1,2)$ and as a means for studying the basic processes of radiation damage production and accumulation.

One disadvantage of the heavy-ion bombardment technique is an inability to adequately simulate the formation of transmutation products such as helium and hydrogen by $(n, \alpha)$ and $(n, p)$ reactions. These are common reactions, and materials exposed to fusion reactor environments may be expected to generate several thousand atomic parts per million (ppm) per year of these elements. ${ }^{(3)}$ These gases may, by migrating to grain boundaries or dislocations, markedly alter the mechanical properties of the materials, and may also influence the formation and growth of the irradiation-produced defect structures. Helium is the most deleterious of the two gases and is the element for which information is most diligently sought. 
Radiation-damage simulation studies involving helium may be conducted by either preinjecting helium in known amounts prior to charged-particle (heavy-ion) irradiation, or by simultaneously bombarding with heavy ions and helium ions. Experimental evidence ${ }^{(4)}$ indicates that differences in injection procedure result in differences in void nucleation and growth behavior. It is desirable, therefore, to demonstrate appropriate injection procedures for simulating reactor environments.

The simultaneous bombardment, or dual-beam, technique requires that two accelerators operate together so that each of the two beams falls upon the same area of the sample surface with the energy and flux of each beam independently controlled. Because the difficulty and expense of operating in this manner is greater than that for operating two accelerators individually, only a few such installations have been successfully operated and results are limited. (5)

This report describes the design, construction, and operating characteristics of a dual-beam bombardment facility at Battelle, Pacific Northwest Laboratories (PNL). The bombardment chamber and those portions of the installation associated with it are described in detail. The accelerators and ion sources are only mentioned briefly, however, as they are commercially produced items for which specific information is already available. Some results of a study of dual-beam irradiation of molybdenum are given.

\section{DUAL-BEAM FACILITY}

The dual-beam capability requires two independently controlled accelerators, one for each ion type, physically situated so that the two beams intersect at the desired spot. To ensure proper experimental control, the type, charge state, energy, and current must be known for each ion beam; and the experimenter should be able to select these parameters. 
The specimen mounting must contain some means for locating the beam cross-over point precisely and for positioning the specimen accurately at that point. The ion-beam lines require a vacuum of $10^{-7}$ to $10^{-8}$ torr, so the specimen chamber must operate at these pressures also. If the specimens are reactive at the irradiation temperatures, the chamber pressures should be as low as the state-of-the-art will allow. The specimen chamber should permit the irradiation of a number of samples at one loading, and preferably provide means for prescribing the thermal history of each sample independently of each of the others. The sample temperatures will depend upon the nature of the experiment being performed. Contemplated fusion reactor design temperatures may be $1000^{\circ} \mathrm{C}$ or higher, so it is essential that the dual-beam facility be capable of operation in this temperature range.

\section{ACCELERATOR SYSTEMS}

A 2-MeV Van de Graaff accelerator manufactured by High Voltage Engineering Company* has been in operation at PNL for several years. At the time the dual-beam facility was proposed, this 2-MeV unit was chosen as a source for light ions ( $\mathrm{He}^{+}$and $\mathrm{H}^{+}$) since it was available and had demonstrated its capabilities satisfactorily.

A 2-MeV tandem accelerator was proposed as a source for heavy ions. A tandem accelerator uses a positively charged terminal to which negative ions are accelerated. Upon reaching the terminal the negative ions are "stripped" of two or more electrons by passing through a foil or a gas stream. The resulting positive ions are thereupon further accelerated to ground potential from the positive terminal. The beam energy, $E$, is given by the formula $E=V(i+i)$, where $V$ is the terminal potential and $i$ is the positive charge on the ion. A singly charged positive ion thus receives $4 \mathrm{MeV}$ from a $2 \mathrm{MV}$ terminal, a doubly charged ion $6 \mathrm{MeV}$, etc. These energies are sufficiently high that the atomic displacements necessary to simulate neutron damage are easily obtained.

\footnotetext{
* Mention of a particular product or manufacturer in this report is for information purposes only; it is not to be construed as a recommendation or endorsement of that product or manufacturer.
} 
The tandem accelerator system procured was the Model 2UDH made by National Electrostatics Corporation. The new tandem accelerator was installed in a specially designed building addition so that the physical requirements for dual-beam operation could be satisfied. A general plan view of the accelerator laboratory is shown in Figure 1.

This tandem accelerator installation can provide beams of $\mathrm{Ni}^{++}$ions of $6-\mathrm{MeV}$ energy and electrical beam currents up to 500 nanoamperes. Up to 50 nanoamperes of $\mathrm{Ta}^{+++}$at $8 \mathrm{MeV}$ has also been generated. These are the ion species currently used; other ions can be obtained by simply interchanging sputtering targets in the source.

The Van de Graaff accelerator can produce up to 20-microampere beams of $\mathrm{He}^{+}$at $2 \mathrm{MeV}$. This is far more $\mathrm{He}^{+}$than is necessary for simulation experiments, which require a current of only a few nanoamperes. Means for reducing the current and for degrading the monoenergetic beam to a distribution of lower energies are incorporated in the beam line and will be discussed later.

\section{BEAM LINES AND BEAM CHARACTERIZATION}

The downstream beam lines with some of the equipment for handling the ion beams are shown in Figure 2. Differential pumping stations are installed between the accelerators and the specimen chambers: a $400-\ell / \mathrm{sec}$ ion pump in the heavy-ion beam 1 ine and a $1000-\ell / \mathrm{sec}$ ion pump in the light-ion beam line. These pumps ensure that there are no slow-pumping volumes near the chamber.

The 1ight-ion beam 1 ine extends from the $0^{\circ}$ port of the Van de Graaff deflection magnet, approximately $8 \mathrm{~m}$ from the bombardment chamber. Near the specimen chamber is a multiply branched cross fitting containing the degrader foils and the energy-sensitive detector for beam characterization. The degradation of the beam is necessary to make the penetration of the light-ion beam equivalent to that of the heavy ions. A 6-MeV Ni ${ }^{++}$ion, from EDEP-1 calculations, ${ }^{(6)}$ penetrates about $1.5 \mu \mathrm{m}$ into a molybdenum sample. $\mathrm{A} \mathrm{He}^{+}$ ion requires only about 300 to $400 \mathrm{keV}$.to penetrate the same distance. By passing the $\mathrm{He}^{+}$beam, typically 1.8 to $2.0 \mathrm{MeV}$, through a suitable thin metal foil, the beam energy is "degraded" to the desired value, and the 


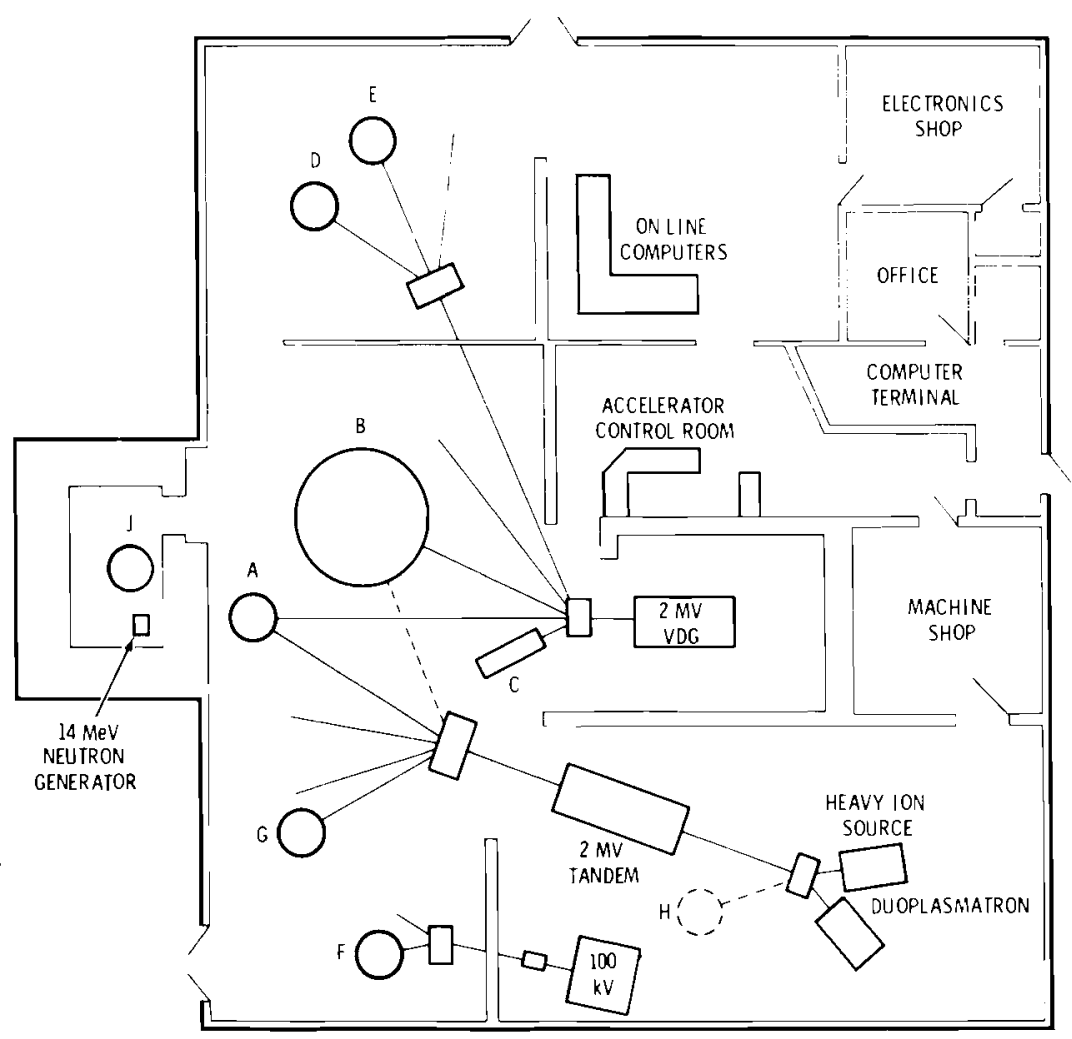

FIGURE 1. Arrangement of the PNL Accelerator Laboratory. The dual-beam experiments are conducted at Position $A$.

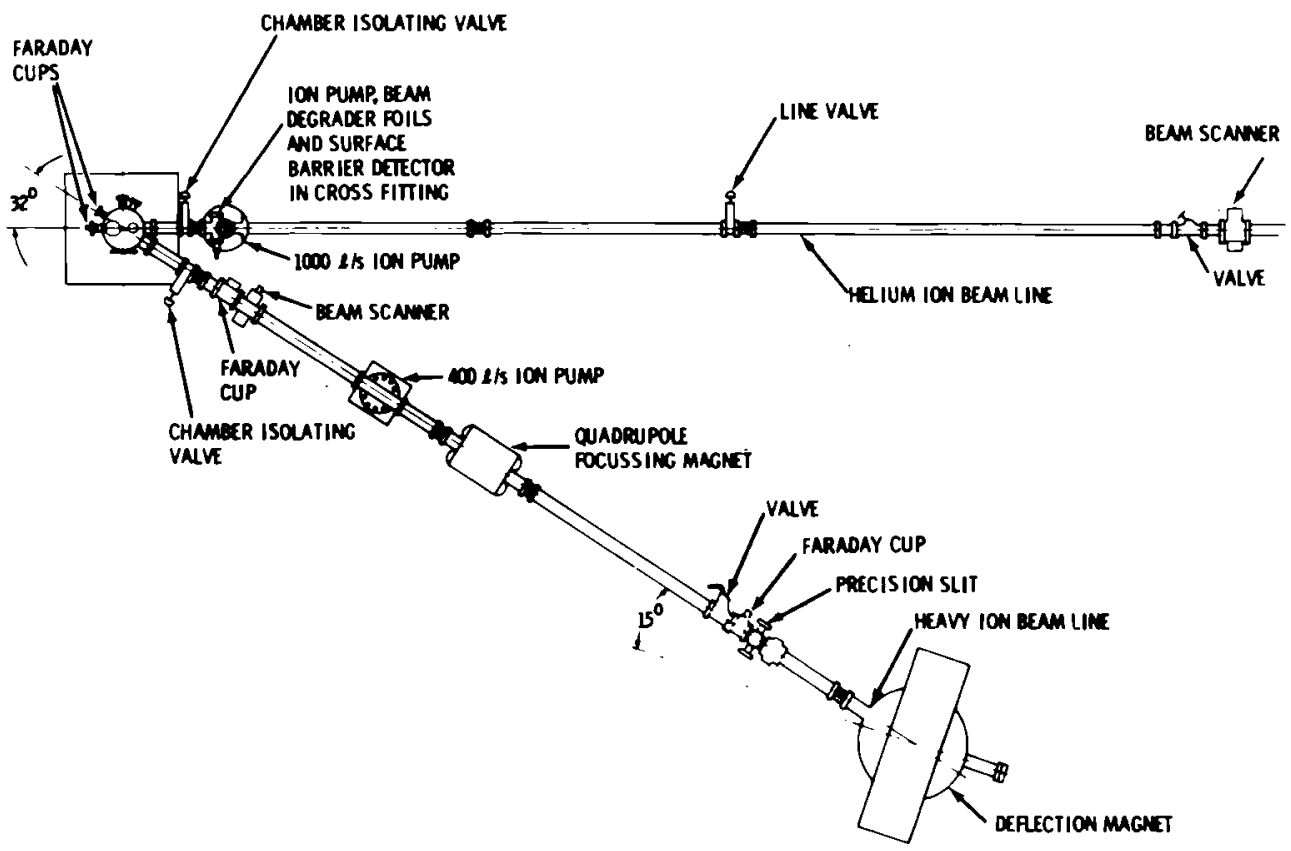

FIGURE 2. Sample Chamber, Beam Lines, and Beam Handling Equipment for Dual-Beam Irradiations. The sample chamber is at the junction of the two beam lines at left. 
monoenergetic beam becomes a spectrum of degraded energies approximately Gaussian in distribution. The degrader system described here employs aluminum foil, nominally $6 \mu \mathrm{m}$ thick, mounted in a holder which can be rotated about an axis perpendicular to the ion beam. The effective thickness is thus variable over a fairly wide range. The foil also scatters the transmitted beam, so both energy and beam current are degraded by the foil. It is necessary to adjust the terminal voltage and beam current as well as the foil thickness to "tune" the beam to a desired current and energy.

The degraded beam energy is measured with a surface-barrier detector. The detector is mounted on a rotary manipulator so that it may be brought into the beam when needed. A 50- $\mu \mathrm{m}$ aperture is incorporated in the detector mounting to reduce the beam intensity (and counting rate) to a usable level and also to help protect the detector from damage. The signal from the surface-barrier detector is displayed after amplification on the screen of a multichannel analyzer. A calibrated pulser produces a reference signal from which the beam energy and energy distribution are determined. Figure 3 shows typical multichannel analyzer displays for different settings of the degrader foil. Energy degrading calculated from EDEP-1 results ${ }^{(7)}$ indicates that the degrader foil is $5 \pm 0.5 \mu \mathrm{m}$ thick. Calculated energy distributions are compared with the multichannel analyzer output in Figure 4.

The heavy-ion beam is directed toward the bombardment chamber by the deflection magnet and is finally focused to the sample position by the quadrupole magnet shown in Figure 2. The beam is scanned by a rotating-wire beam scanner just outside the entry port of the sample chamber. An oscilloscope display of the beam scanner output provides a rapid visual appraisal of the beam cross section. Maximum utilization of the beam occurs when the beam diameter is equal to or less than the sample diameter. In practice, however, the beam is made larger to afford a more nearly uniform beamintensity cross section. This will be explained further in a later section of this report. 
(a)

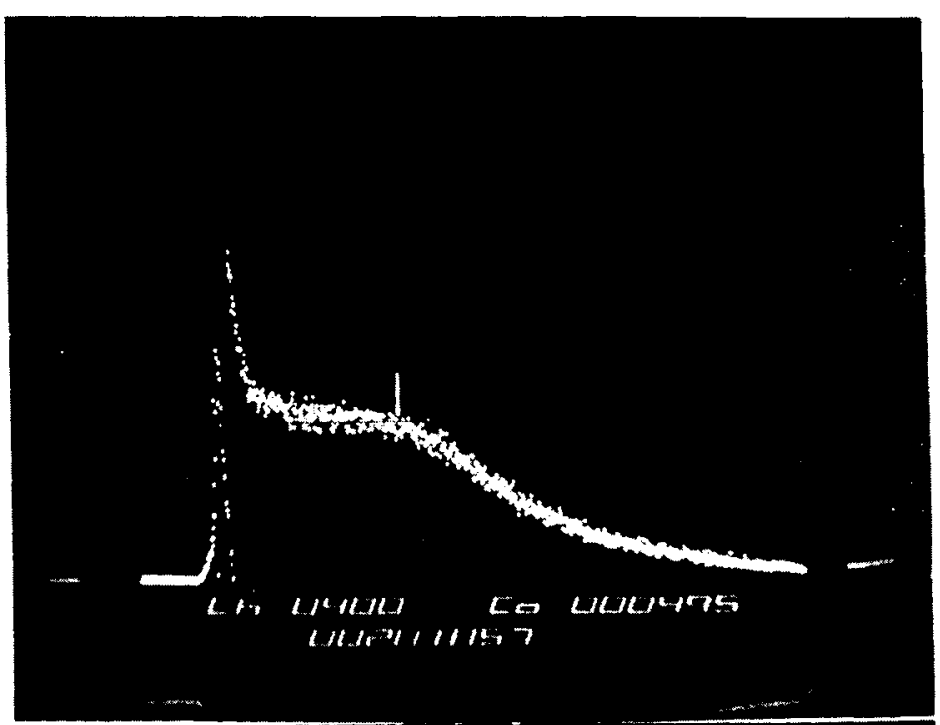

(b)

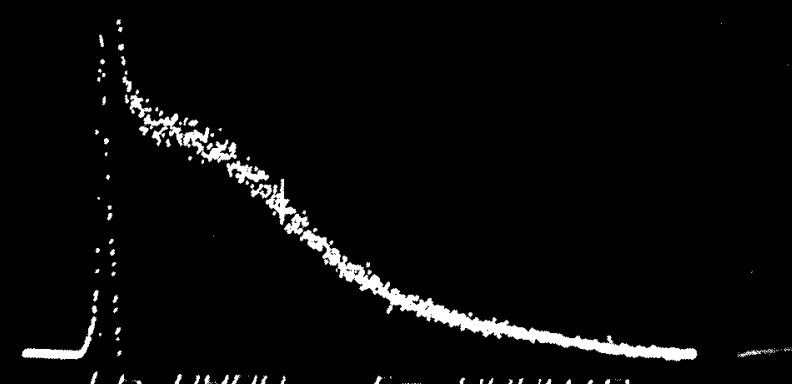

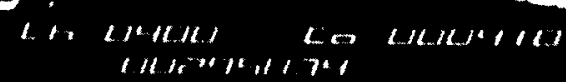

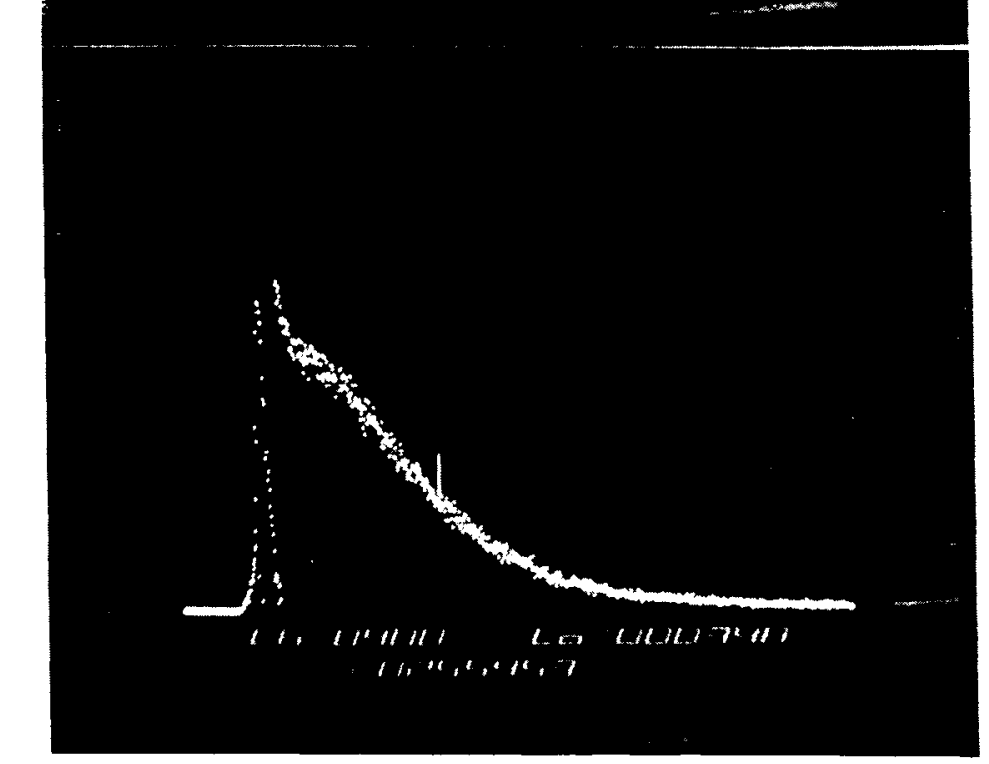

FIGURE 3. Multichannel Analyzer Displays of $\mathrm{He}^{+}$Beam Energies Showing Effect of Degrader Foil. In (a), the foil is perpendicular to the beam; in (b), (c), and (d), the foil is tilted respectively $20^{\circ}, 30^{\circ}$, and $40^{\circ}$ from the (a) position. The channel cursor indicates $400 \mathrm{keV}$ in each case. 
FOIL NORMAL IS

PARALLEL TO BEAM

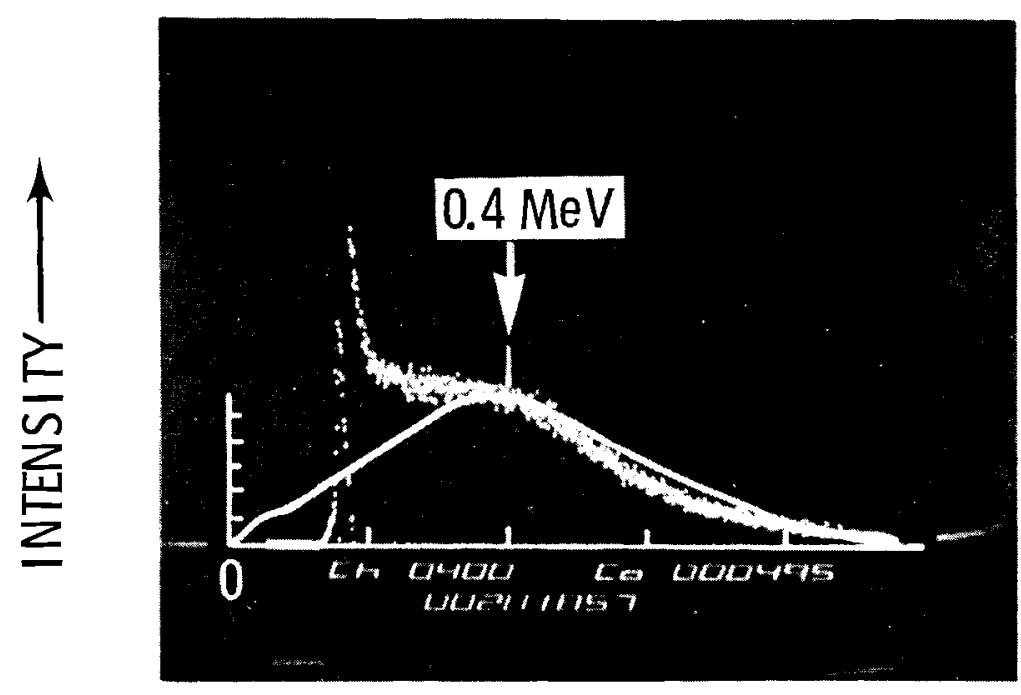

ENERGY
FOIL NORMAL IS

$30^{\circ}$ FROM BEAM

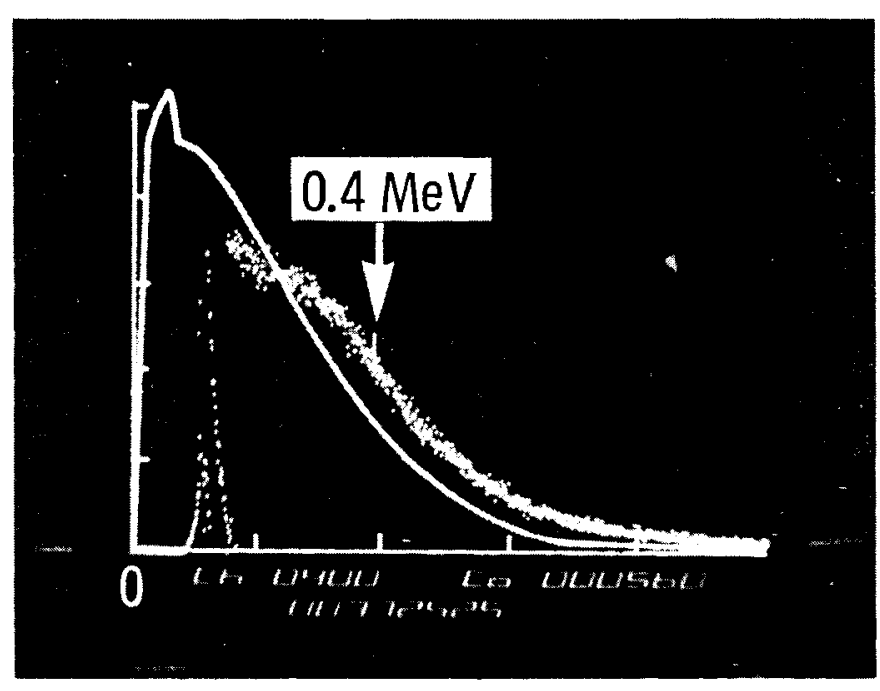

ENERGY $\rightarrow$

FIGURE 4. Calculated Energy Distributions Compared with Multichannel Analyzer Outputs for the Foil Normal to the Beam and Tilted $30^{\circ}$. The energies were calculated assuming an aluminum degrader foil of thickness $5 \pm 0.5 \mu \mathrm{m}$. 


\section{BOMBARDMENT CHAMBER}

The bombardment chamber is at the point of intersection of the heavy-ion and light-ion beam lines. The chamber is based upon a Varian FC 12 ion pump unit of $200 \mathrm{l} / \mathrm{sec}$ capacity. The chamber proper is a $12-\mathrm{in} .(30.5 \mathrm{~cm})$ diameter stainless steel bell jar. Access to the chamber is by a copper gasket Wheeler* flange which forms the top of the bell jar and to which the sample holder assembly is attached.

The specimen holder assembly consists of a precision manipulator with $x, y, z$, and rotational adjustments. The manipulator carries a circular stainless steel element to which the sample holders and electrical components are attached. Figure 5 shows the relationship of the various parts and will serve as a guide for the remaining description. The specimen holder assembly will henceforth be referred to by the more descriptive term "carrouse1."

The samples for which the chamber was designed are electron microscope specimen discs, $3 \mathrm{~mm}$ in diameter and 0.05 to $0.10 \mathrm{~mm}$ thick. Eight such discs can be irradiated at each loading. Each disc is mounted upon its own heater and is brought individually into bombardment position by rotation of the carrousel. Electrical switching is also accomplished by the carrousel rotation so that only the sample positioned for irradiation may be heated. The thermal history of each sample is thus independent of that of the other samples, which is a departure from the more common practice of heating all samples in a single furnace.

The individual sample heaters are shown in Figure 6. A molybdenum body contains a toroidal tungsten-rhenium alloy heating element embedded in a refractory alumina cement. A centrally located thermocouple may be used for temperature measurement, with the alumina thermocouple tube serving as a mounting and stand-off for the furnaces. The thermocouple leads are magnetically switched by the carrousel rotation so that only the sample being heated is connected to the temperature measurement system.

\footnotetext{
ॠWeeler flanges are a proprietary design of Varian Vacuum Division, Varian Associates.
} 


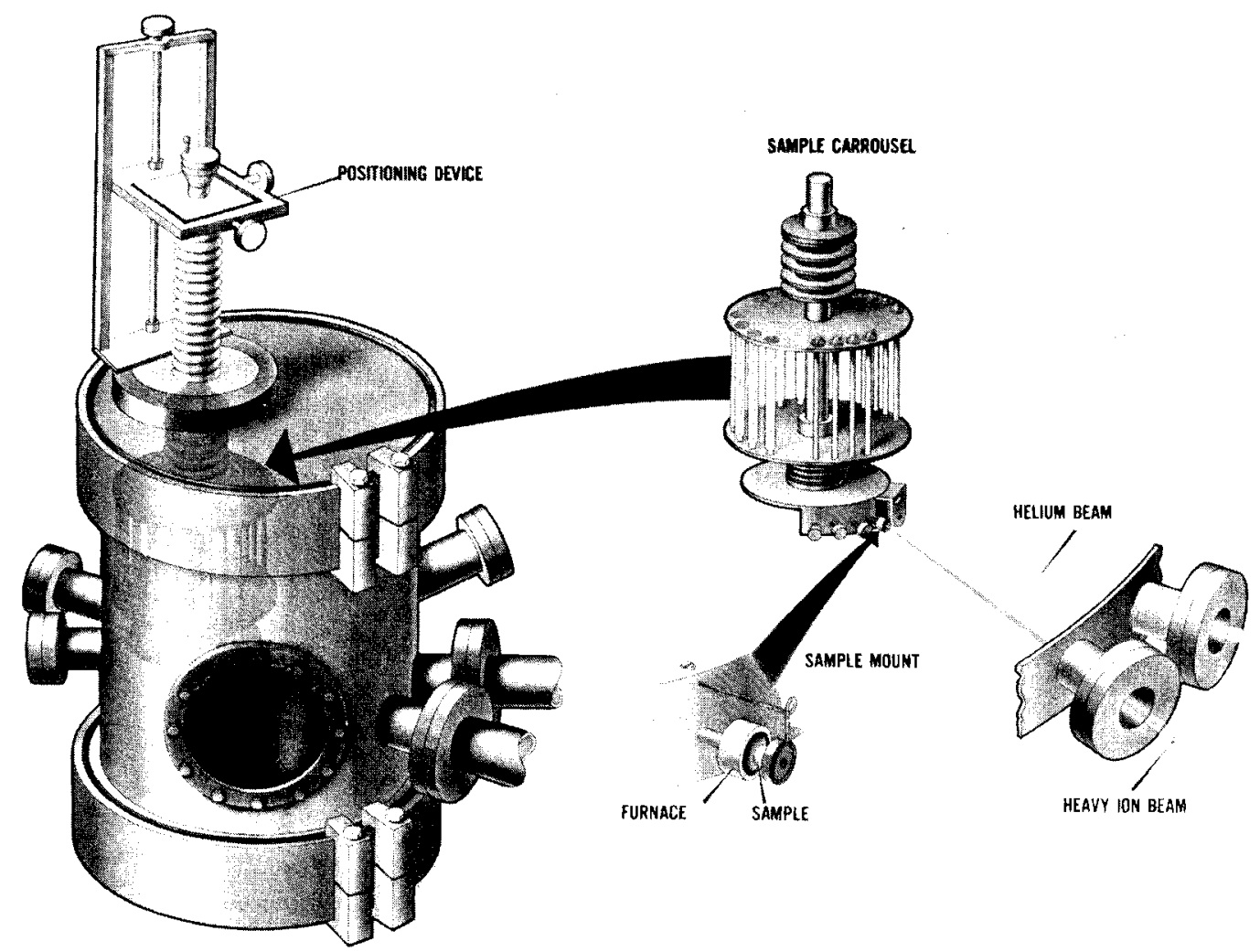

FIGURE 5. Sample Chamber and Carrousel with Detail of Sample Mounting. The vertical rods at the front of the carrousel are electrical contactors for switching the heater current. At the rear are magnetically operated switches for the thermocouple leads. For simplicity, the actual wiring is not shown.

These heaters have been operated as high as $1200^{\circ} \mathrm{C}$ for extended periods without failure. No attempt has been made so far to reach a higher temperature, al though they could probably reach $1400^{\circ} \mathrm{C}$ to $1500^{\circ} \mathrm{C}$ with a corresponding decrease in 1 ifetime.

The sample discs are positioned at the center of the heater faces by insulating refractory rings, each held in place by a molybdenum wire spring loop. The sample and furnace outer body are electrically isolated from the other components and are connected to an electrometer for measuring sample current during irradiation. Because of the internal switching provisions, only four leads are required to penetrate the vacuum wall: two for the thermocouples and one each for the heater and beam current circuits. 


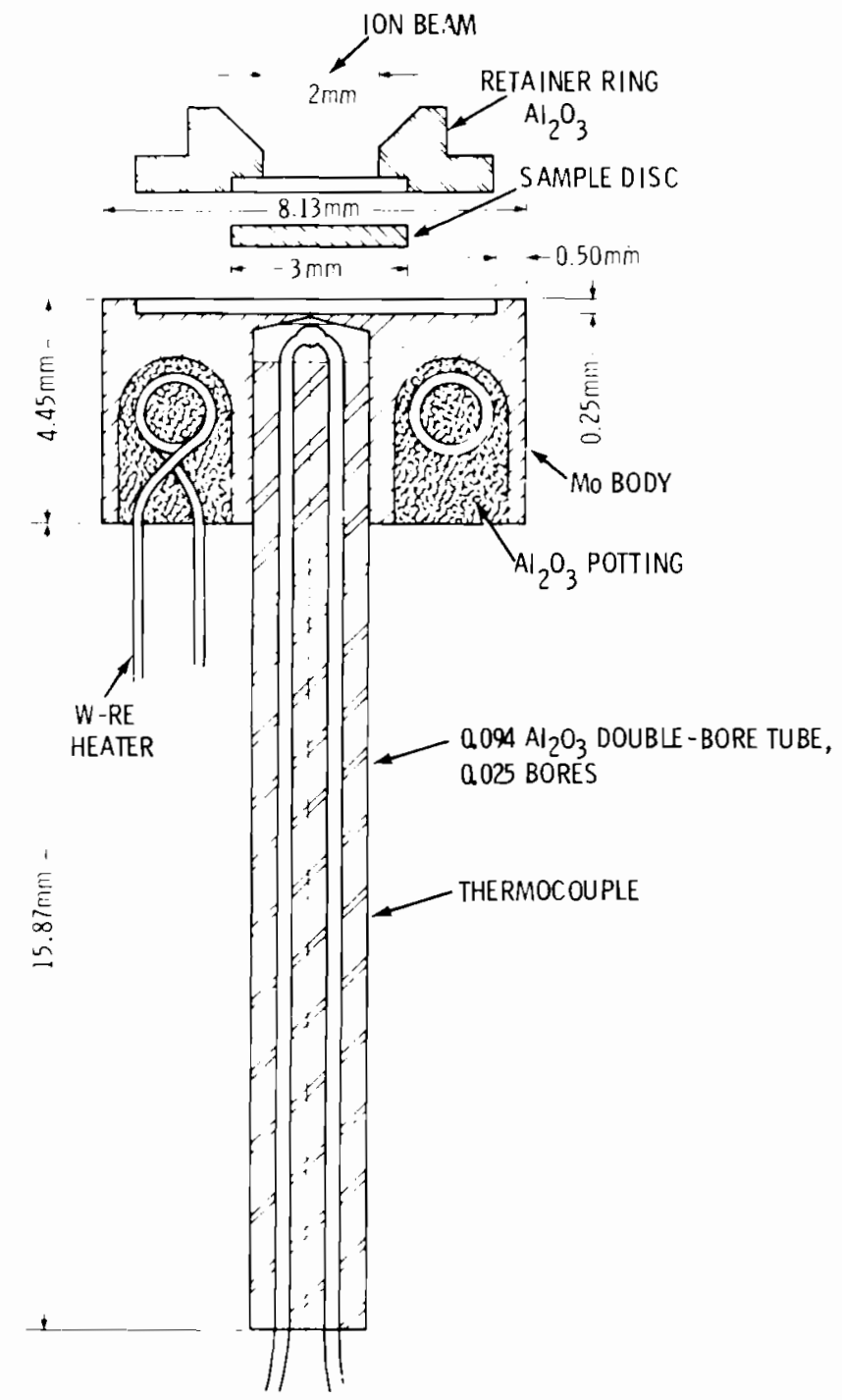

FIGURE 6. Construction of the Individual Sample Heaters

The helium beam enters the chamber through a 3-mm collimator aperture. This collimator, $30 \mathrm{~cm}$ from the degrader foil, provides a well-defined beam having no more than $10 \%$ variation in intensity across the beam cross section.* A similar aperture, $6 \mathrm{~mm}$ in diameter, is placed in the heavy-ion beam entrance port; it has no collimation function but serves as a pumping impedance

*Determined with the aid of the $2-\mathrm{mm}$ alignment aperture. Variations over a smaller area are possible but unlikely in view of the geometry of the system. 
separating the chamber from the beam line. The alignment procedure, discussed later, requires that the heavy-ion beam be steered to the cross-over point; hence a fixed collimator cannot be used.

Alignment of the specimen carrousel with the beam is facilitated by the inclusion of a $3-\mathrm{mm}$ by $5-\mathrm{mm}$ quartz crystal and a $2-\mathrm{mm}$ aperture in the sample holder assembly. Alignment is carried out by ensuring that each of the two beams passes through the $2-\mathrm{mm}$ aperture, which is the same radial distance and the same height as the sample discs. Once alignment is verified, turning the carrousel to the next sample position automatically indexes that sample into bombardment position.

Two Faraday cups at the back of the chamber measure the beam currents independently when the carrousel is raised out of the beam and are also used in the alignment procedure described later.

An alternative current-measuring system is located at the entrance side of the chamber. This system utilizes a swinging paddle-shaped electrode arranged so that it can intercept either of the two beams. The paddle is enclosed in a biased suppressor cage, which is open front and rear to allow beam passage. The purpose of this device is to allow intermittent monitoring of the individual beams during long irradiations without disturbing sample alignment or temperature control. Since only two or three seconds are sufficient for a current reading, the effect on the experiment is minimal. These readings supplement the measurements of sample currents taken directly from the sample holder.

\section{CHAMBER ENV IRONMENT}

Most of the refractory metals (molybdenum, tungsten, niobium, tantalum, vanadium) are capable of dissolving and/or reacting with the residual gases in the vacuum chamber when at elevated temperatures. It is necessary to reach the lowest pressures possible when these samples are being heated, and it is also desirable that the constitution of the residual gases be monitored during the experiment. Therefore, a quadrupole residual gas analyzer capable 
of detecting residual partial pressures of $2 \times 10^{-11}$ torr is incorporated into the chamber. It is also useful during routine pumping operation for detecting leaks and for showing the presence of undesired hydrocarbon contamination from pump oils or unsatisfactorily cleaned surfaces.

The bell jar and carrousel assembly contain no organic materials and are completely bakeable. Heating elements are incorporated into the lower part of the sample chamber, while a separate two-piece shroud may be placed over the upper part of the bell jar. The leads to the carrousel and to the Faraday cups must be removed. The bakeout shroud does not enclose the line valves or the beam scanner. Neither of these items are bakeable to $350^{\circ} \mathrm{C}$, which is the temperature inside the shroud. After bakeout, the chamber pressure will be no higher than $3 \times 10^{-9}$ torr and is often much lower.

\section{TEMPERATURE MEASUREMENT AND CONTROL}

Sample temperatures are measured during irradiation with an infrared pyrometer through a glass viewing port in the sample chamber. The output of the infrared pyrometer is fed to the furnace temperature controller. Although the furnaces contain thermocouples, the pyrometer provides quicker response and can detect the heating effects of the ion beam on the sample surface. The optical viewing system on the pyrometer contains a sighting reticle which is also used for sample alignment.

The largest source of potential error in the use of the pyrometer arises from the uncertainty in the values of surface emissivity. Emissivity varies from sample to sample, with surface preparation, polishing technique, or amount of oxidation. Whenever possible, the temperatures indicated by the thermocouples are used to estimate the emissivity values to which the pyrometer is adjusted.

\section{OPERATION AND PROCEDURE}

The procedures and operation methods used in the dual-beam facility include loading the samples into the furnace assemblies, preparation for and the beginning of dual-beam irradiation, and the recording of experimental results. 


\section{LOADING}

The samples are loaded into the furnace assemblies with the carrousel removed from the chamber and placed in a horizontal position. A procedure which has been found most effective is to moisten the sample with a drop of ethyl alcohol, place it in the refractory guard ring to which it adheres by surface tension, then place the two temporarily joined pieces under the retaining spring loop. Care must be taken not to exceed the elastic limit of the molybdenum wire spring. Usually slight adjustments are necessary to ensure that the guard ring is flat against the furnace surface and that the specimen is held securely. After all eight specimens are loaded, the carrousel is lifted to its normal vertical position and the specimens again examined closely to ensure that none have slipped out of position. When everything is satisfactory, the flange bearing the carrousel is lifted into position and bolted down.

Two sorption pumps are used to rough pump the system to $<10^{-2}$ torr, whereupon the chamber isolation valve is opened and the ion pumps take over the pumping operation. Valves shut off the sorption pumps at this point. If bakeout is not required, the system will usually reach $\sim 10^{-7}$ torr in about $3 \mathrm{hr}$. Bakeout requires a $4-\mathrm{hr}$ bake cycle followed by overnight cooling. As a rule, vacuum leaks are encountered only after continued reuse of the Wheeler flange gasket and are eliminated by replacing the gasket.

\section{IRRADIATION PROCEDURE}

Preparation for a dual-beam irradiation begins by bringing both accelerators into operation. The carrousel is raised from the paths of the beams, and the Faraday cups at the back of the chamber are used to confirm that both beams enter the chamber and are of the correct intensity. The heavy-ion beam is then temporarily stopped by either the swinging paddle or one of the upstream Faraday cups so that the helium beam may be adjusted. The degrader foil is introduced and the transmitted energy distribution determined by the surface-barrier detector. The detector is never used in the direct undegraded beam because serious damage or destruction might result. Adjustments of the 
degrader foil tilt angle, the accelerator terminal voltage, and beam current are then performed as necessary to secure the desired energy and current in the degraded beam.

At this point the carrousel is lowered and the 2-mm alignment aperture centered in the $\mathrm{He}^{+}$beam. The heavy-ion beam is then introduced and directed by adjustments of the steering devices and the quadrupole until one-half the total intensity passes through the 2-mm aperture. Assuming the beam profile to be approximately Gaussian, this alignment operation assures an intensity profile varying from $100 \%$ to $80 \%$ of the maximum intensity. The beam scanner provides visual confirmation of the beam profile.

When both beams fal1 upon the 2-mm aperture and the beam currents are correct, the irradiation is started. The reticle on the optical viewer of the infrared pyrometer is placed precisely upon the 2-mm alignment aperture and both ion beams momentarily interrupted. The first sample is then aligned carefuliy with the reticle, brought to the desired temperature, and the temperature controller switched into the heater circuit. The ion beams are then turned on and the irradiation begins.

Both sample temperature and sample beam current are recorded on a two-pen recorder. The sample beam current is that current recorded directly by the electrometer connected to the sample. It is, in effect, an unsuppressed Faraday cup with a further perturbation by thermionic emission from the heater leads. This current reading provides only the qualitative information that the current is or is not constant. The actual currents are monitored intermittent1y (usually 3-min intervals in long irradiations) and the currents are recorded on a $\mathrm{log}$ sheet. At the end of the irradiation, the alignment aperture is again used to verify that the beam shape and position have not changed. Beam stability is usually very good, with no measurable shift in beam position observed if steering and magnet controls are not disturbed. Occasional failures occur in the source and other upstream accelerator components. Such beam interruptions are obvious immediately, the experiment is terminated at once, and a11 pertinent data are entered on the $10 \mathrm{~g}$ sheet. 


\section{EXPERIMENTAL RECORDS}

A separate $\log$ sheet is prepared for each sample. It lists the sample material, its identification number, the type of ion or ions, the ion energies and the goal fluences. Also logged are the beam currents recorded by the Faraday cups with and without the 2-mm aperture and the corresponding currents measured with the paddle. As the experiment progresses, the beam currents are monitored intermittently; these values and the corresponding elapsed times are recorded. Temperatures are recorded automatically but are also entered at frequent intervals in the log. At the end of the irradiation the beam currents and alignment are again measured and recorded.

The heavy-ion beam currents usually drop slightly during a longer experiment due to changes in the source characteristics with time. However, if no change is made in the beam steering or quadrupole settings, the beam remains in alignment with the sample. The beam currents are thus measurable with minimal error. A larger error arises from the nonuniformity of the beam, particularly in a deviation from the assumed Gaussian intensity profile. This may be $20 \%$ or more, resulting in an uncertainty of perhaps $30 \%$ in the estimation of ion beam fluence on a given sample area. This is not especially unreasonable for experiments of this type.

As mentioned earlier, the largest source of error in the temperature measurement lies in estimating the emissivity values. This error is larger at lower temperatures. Comparisons with temperatures determined by thermocouples lead to typical errors of $\pm 10^{\circ}$ at $1000^{\circ} \mathrm{C}$ to $\pm 100^{\circ}$ at $300^{\circ} \mathrm{C}$. At the lower temperatures the thermocouple becomes the more reliable indicator. Most of the irradiations performed to date have been in the temperature range of $900^{\circ}$ to $1200^{\circ} \mathrm{C}$ so there has been no necessity to operate in the thermocouplecontrolled mode.

\section{DUAL-BEAM IRRADIATION OF MOLYBDENUM AT $1000^{\circ} \mathrm{C}$}

Recent studies have shown a significant effect of helium on void formation in nickel after simultaneous bombardment with $\mathrm{Ni}^{++}$ions and $\mathrm{He}^{+}$ions. (4) The magnitude of the effect has been related to the rate at which the helium 
is introduced during bombardment. It is also expected that the effect of helium will depend on the atom displacement rate due to the heavy ions and to the temperature.

For the initial experiments with the new dual-beam irradiation facility, molybdenum was bombarded at very low dose rates, $3 \times 10^{-4} \mathrm{dpa} / \mathrm{sec}$, with and without the simultaneous bombardment of helium. Investigations utilizing the dual-beam irradiations are in progress that will examine the critical regions of damage rate and temperature where helium effects are most pronounced in ion-bombarded molybdenum.

\section{MATERIAL AND IRRADIATION CONDITIONS}

High purity, polycrystalline molybdenum foil was annealed at $1600^{\circ} \mathrm{C}$ for $2 \mathrm{hr}$ just prior to bombardment. The specimens were vibra-polished to a smooth surface and electropolished prior to the annealing. Next, they were bombarded with $5-\mathrm{MeV} \mathrm{Ni}{ }^{++}$ions at a current density of $6 \times 10^{11}$ ions $-\mathrm{cm}^{2} / \mathrm{sec}$ at $1000^{\circ} \mathrm{C}$. An intensity profile of the beam is nearly Gaussian in shape and nominally about 3 to $3.5 \mathrm{~mm}$ in width at the half maximum. Only the center $2 \mathrm{~mm}$ of the beam strikes the specimen. In some of the experiments, the beam scanner nearest the target was not working properly, and there were indications from irregularities in the damage pattern that the beam was not uniform in shape but rather oblong. This gives rise to error of \pm a factor of 2 in the reported dose values.

The damage profile for $5-\mathrm{MeV} \mathrm{Ni}{ }^{++}$ions incident on molybdenum is shown in Figure 7. This is a calculated profile using the EDEP-1 code developed at Naval Research Laboratory. ${ }^{(6)}$ Recent studies on the damage profile in ion-bombarded molybdenum have shown the actual profile to be broader than that shown in Figure $7 .{ }^{(8)}$ In fact, from 0.5 to $1.0 \mu \mathrm{m}$, there is little variation in magnitude of the observable damage.

For those specimens bombarded simultaneously with helium, a helium current of $6 \times 10^{9}$ ions $-\mathrm{cm}^{2} / \mathrm{sec}(0.0025 \mathrm{ppm} / \mathrm{sec}$ at the region of maximum helium concentrations) was used. The energy distribution of the $\mathrm{He}^{+}$ions 


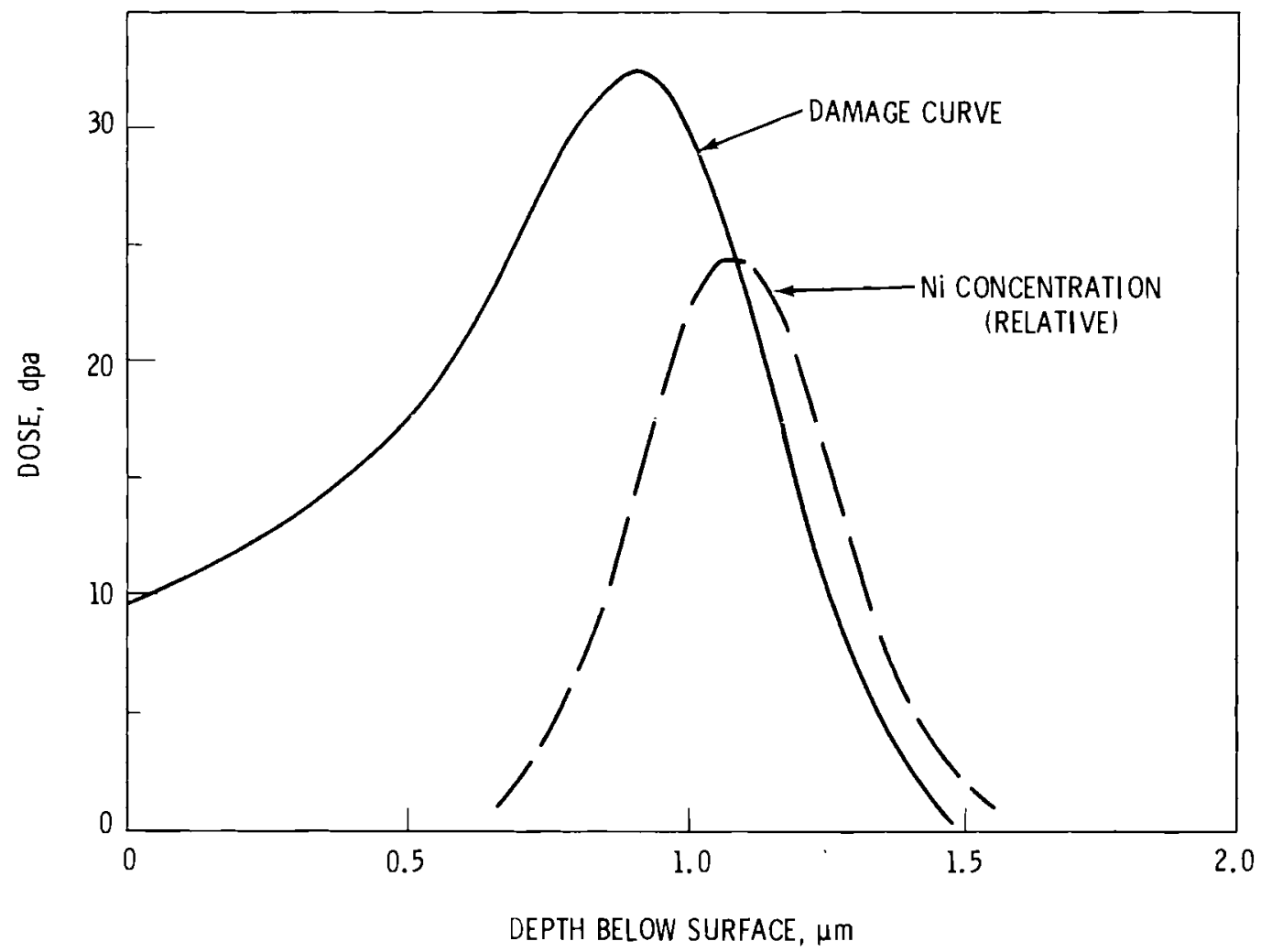

FIGURE 7. Damage Curve for $5-\mathrm{MeV} \mathrm{Ni}^{++}$Ions on Molybdenum and Distribution of Deposited $\mathrm{Ni}^{++}$Ions

exiting from the degrader foil is approximately Gaussian. A trace of the $\mathrm{He}^{+}$ ion energy distribution measured on the multi-channel analyzer is shown in Figure 4. The helium penetration into the molybdenum as a function of energy was calculated using the EDEP-1 program. Tabulated values from Northcliffe and Schiling for the electronic stopping power were used in the case of $\mathrm{He}^{+}$ ions. (9) By knowing the depth of penetration as a function of energy and the energy distribution, the distribution of helium as a function of depth can be computed. The helium distribution computed in this fashion is shown in Figure 8 for a degrader foil thickness of $5 \pm 0.5 \mu \mathrm{m}$. 
(a)

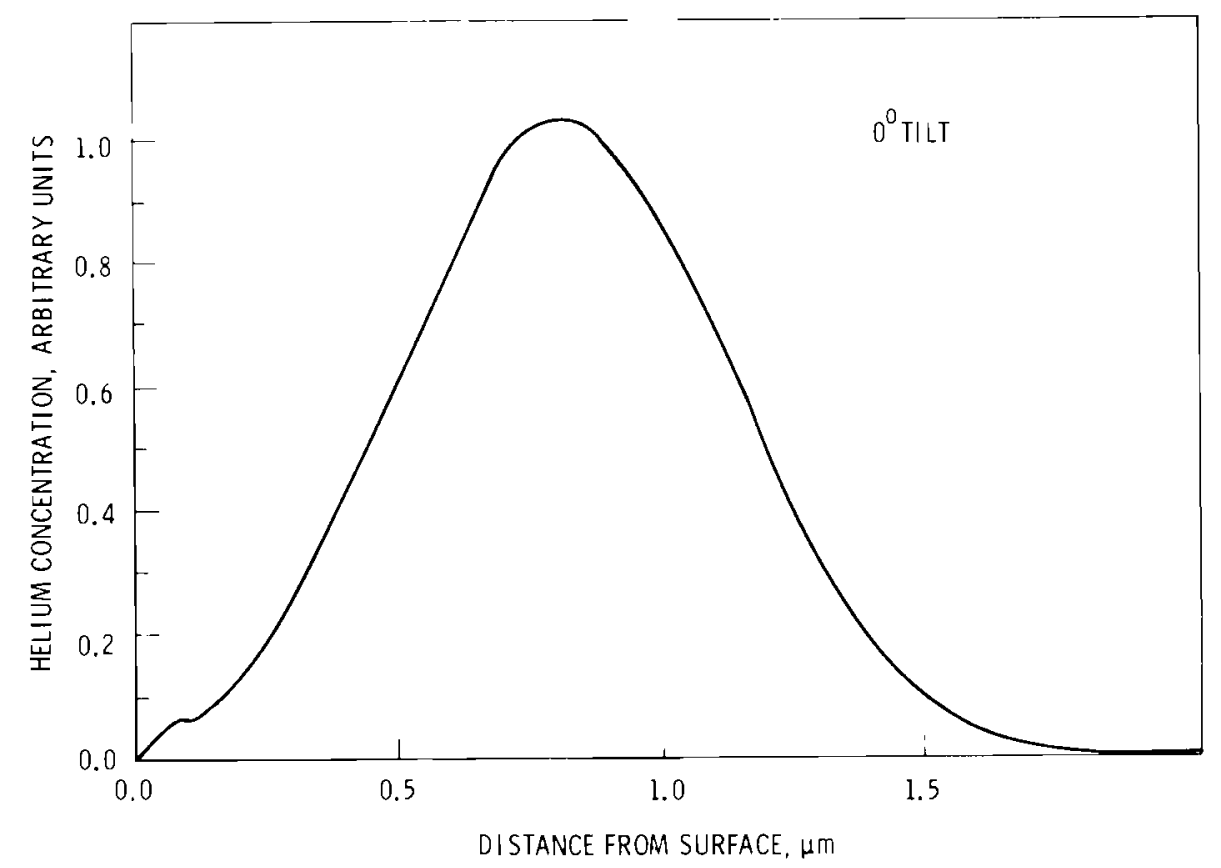

(b)

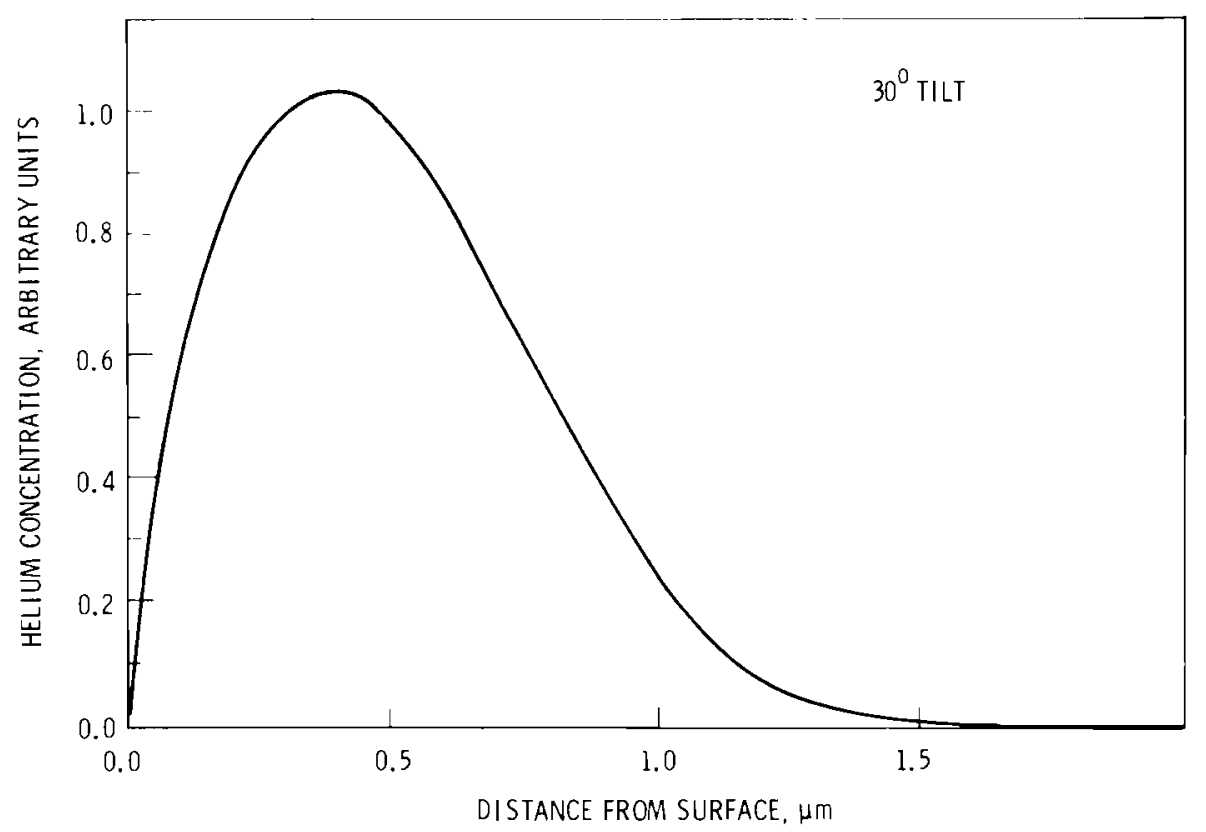

FIGURE 8. Distribution of Deposited Helium in Molybdenum for a Degrader of Thickness $5+0.5 \mu \mathrm{m}$ : (a) Normal to the beam, and (b) tilted by $3 \overline{0}^{\circ}$ 


\section{POST-IRRADIATION EXAMINATION}

After bombardment, all the specimens were electrolytically polished to remove $0.5 \pm 0.05 \mu \mathrm{m}$ of material from the bombarded surface. Final polishing to sufficiently thin material was from the nonbombarded side. The observed damage and helium concentration would then correspond to a region 0.5 to $0.6 \mu \mathrm{m}$ from the free surface.

Small uncertainties in surface removal and variation in the energy of the degraded helium beam during the irradiation produce uncertainties in the amount of helium expected in the region of observations. Because of the broad distribution of helium, however, the reported values are within $50 \%$ of the actual value. For experiments of this type, this is sufficiently accurate.

\section{RESULTS AND DISCUSSIONS}

The microstructure was analyzed by standard transmission electron microscopy techniques for the void size, void number density, void volume fraction and dislocation density. The microstructural data for two dose levels are compared in Table 1. A comparison of the microstructure at the high-dose levels for specimens with and without helium is shown in Figure 9.

These results, while limited in scope, do illustrate the importance of helium in promoting void nucleation during ion bombardment. In the specimen with the helium, void growth is still very limited up to the dose of $2 \mathrm{dpa}$. In the specimen without helium, void growth is more pronounced in the dose interval from 0.35 to $2.0 \mathrm{dpa}$. In this case, the vacancies generated by the bombardment prefer to go to existing voids rather than nucleate new voids.

These results contrast sharply with previous results on molybdenum bombarded simultaneously with $\mathrm{Ni}^{++}$and $\mathrm{He}^{+}$ions in which no effect of helium was detected. (10) In that work, the dose rate from the heavy ions was much higher--2 $\times 10^{-2} \mathrm{dpa} / \mathrm{sec}$. Wiedersich and $\mathrm{Ha} 1 \mathrm{l}^{(11)}$ have shown that, other parameters being equal, the void nucleation rate increases with the damage rate. At very high dose rates, the effect of helium can be completely masked, since helium is no longer required for void nucleation. However, the dose rate at which helium becomes relatively unimportant is a function of 


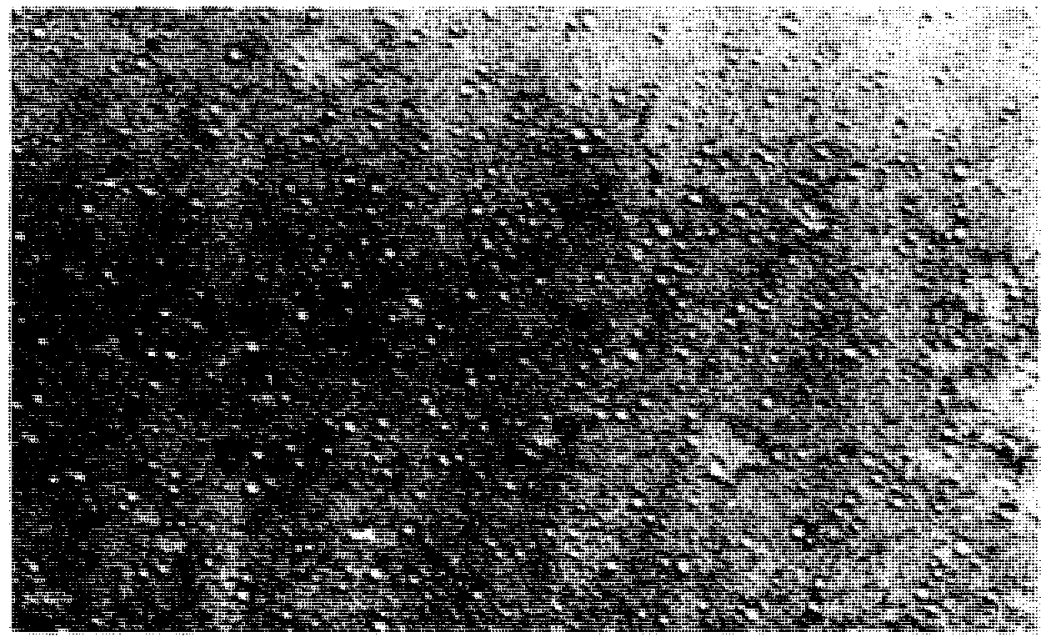

(a) $0.4 \mathrm{dpa}, 2$ appm He

N

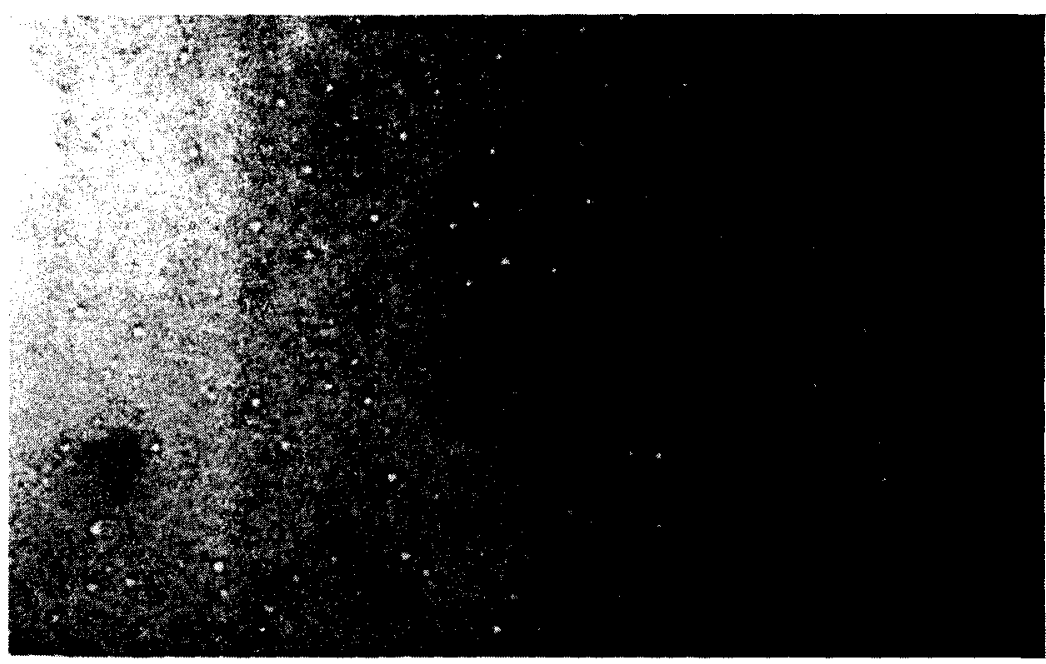

(c) $0.35 \mathrm{dpa}, 0 \mathrm{He}$

$240,000 x$

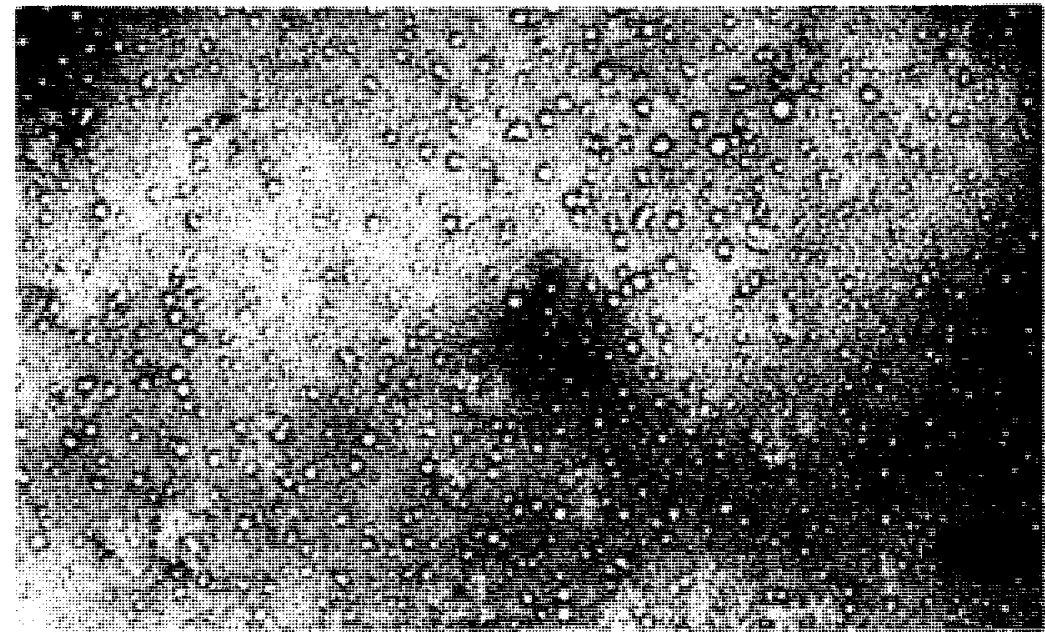

(b) $2.0 \mathrm{dpa}, 4 \mathrm{appm} \mathrm{He}$

$240,000 x$

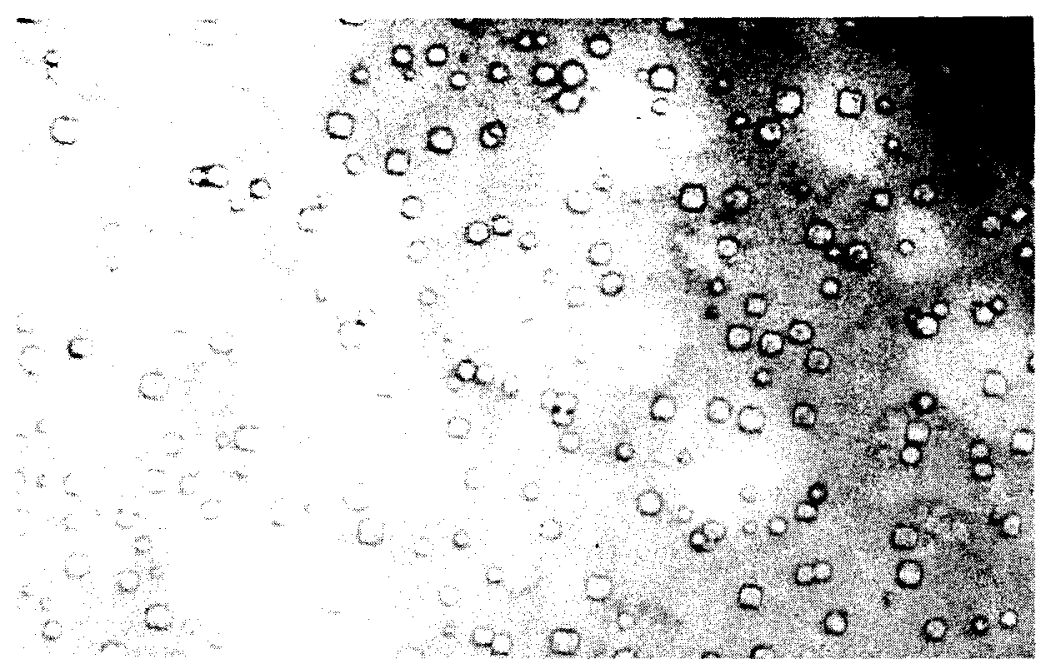

(d) $2.0 \mathrm{dpa}, 0 \mathrm{He}$

$100,000 x$

FIGURE 9. Typical Microstructures of Molybdenum Bombarded with $5 \mathrm{MeV} \mathrm{Ni}^{++}$and $200 \mathrm{KeV} \mathrm{He}^{+}$Ions 
TABLE 1. Microstructural Parameters in Molybdenum Bombarded with $5-\mathrm{MeV} \mathrm{Ni}^{++}$and $200-\mathrm{keV} \mathrm{He}^{+}$ Ions

$\begin{array}{cccccc}\text { Specimen } & \begin{array}{l}\text { Dose } \\ (\mathrm{dpa})\end{array} & \begin{array}{c}\mathrm{He} \\ (\mathrm{ppm})\end{array} & \begin{array}{c}\overline{\mathrm{d}} \text { void } \\ (\mathrm{nm})\end{array} & \begin{array}{c}\rho \text { void } \\ \left(\mathrm{m}^{-3}\right)\end{array} & \begin{array}{c}\Delta \mathrm{v} / \mathrm{v} \\ (\%)\end{array} \\ 1 & 0.4 & 2 & 3.3 & 5 \times 10^{22} & 0.1 \\ 2 & 2.0 & 4 & 3.3 & 1 \times 10^{23} & 0.18 \\ 3 & 0.35 & \text { None } & 3.0 & 3 \times 10^{21} & 0.01 \\ 4 & 2.0 & \text { None } & 16.0 & 3 \times 10^{21} & 0.09\end{array}$

temperature. Investigations to date indicate that for temperatures of $\leq 1000^{\circ} \mathrm{C}$, helium will affect void nucleation for damage rates less than about $5 \times 10^{-3} \mathrm{dpa} / \mathrm{sec}$.

\section{ACKNOWLEDGMENTS}

The authors wish to acknowledge the contributions of many individuals who assisted in the design and construction of the various components. Mr. Richard Tokarz, Engineering Physics Department, designed the bell jar and vacuum system and arranged its construction. The carrousel design is largely the work of Mr. J. L. Humason, Materials Department. Discussions with Mr. E. R. Bradley, Dr. D. L. Styris, and Dr. P. L. Hendrick provided invaluable guidance. Finally, the cheerful and willing cooperation of Mr. W. A. Glass and the staff of the Accelerator Laboratory helped overcome what would otherwise have been formidable obstacles. 


\section{REFERENCES}

1. G. L. Kulcinski, Nuclear Instruments and Methods, 94:365-375, 1975.

2. C. H. McHargue, IEEE Transactions of Nuclear Science, NS22, $\underline{3}: 1743-1748$, 1975.

3. G. L. Kulcinski, D. G. Doran, and M. A. Abdou, "Comparison of Displacement and Gas Production Rates in Current Fission and Future Fusion Reactors," Properties of Reactor Structural Alloys after Neutron or Particle Irradiation, ASTM STP 570, American Society for Testing and Materials, pp. 329-351, 1975.

4. J. L. Brimhall and E. P. Simonen, "Effect of Helium on Void Formation in Nickel," to be published in Journal of Nuclear Materials.

5. Proceedings on Experimental Methods for Charged-Particle Irradiations, U.S. Energy Research and Development Administration Report, CONF-750947, David Kramer, Editor, 1975.

6. J. Manning and G. Mueller, Computer Physics Communications, 7:85, 1974.

7. E. P. Simonen and J. L. Brimha11, Transactions of the American Nuclear Society, 27:329, 1977 .

8. C. H. Henager, Jr., J. L. Brimhall and E. P. Simonen, "The Damage Profile in Mo Bombarded with $\mathrm{Ni}^{++}$and $\mathrm{Ni}^{++}+\mathrm{He}^{+}$Ions, to be published in Radiation Effects.

9. L. C. Northcliffe and R. F. Schilling, Nuclear Data, A7:233, 1970.

10. J. L. Brimha11, In: Proceedings of Consultants Symposium on the Physics of Irradiation-Produced Voids, AERE-R7934, Edited by R. S. Nelson, AERE, Harwe11, England, p. 177, 1974.

11. H. Wiedersich and B. 0. Ha11, Journal of Nuclear Materials, 66:187, 1977. 



\section{DISTRIBUTION}

No. of

Copies

\section{OFFS ITE}

A. A. Churm

DOE Chicago Patent Group

9800 South Cass Avenue

Argonne, IL 60439

2 L. C. Ianniello

Materials Science Division

Office of Basic Energy Science

Department of Energy

Washington, DC 20545

S. A. Wolfe

Materials Science Division

Office of Basic Energy Science

Department of Energy

Washington, DC 20545

F. V. Nolfi

Argonne National Laboratory

$9700 \mathrm{~S}$. Cass Avenue

Argonne, IL 60439

P. R. Okamoto

Argonne National Laboratory

$9700 \mathrm{~S}$. Cass Avenue

Argonne, IL 60439

H. Wiedersich

Argonne National Laboratory

$9700 \mathrm{~S}$. Cass Avenue

Argonne, IL 60439

A. N. Goland

Brookhaven National Laboratory Upton, NY 11973

D. M. Parkin

Los Alamos Scientific Laboratory

P.0. Box 1663

Los Alamos, NM 87544

227
No. of

Copies

K. Farrell

Oak Ridge National Laboratory

P.0. Box $X$

Oak Ridge, TN 37830

L. K. Mansur

Oak Ridge National Laboratory P.0. Box X

Oak Ridge, TN 37830

T. S. Noggle

Oak Ridge National Laboratory P.0. Box $X$

Oak Ridge, TN 37830

N. H. Packan

Oak Ridge National Laboratory P.0. Box $X$

Oak Ridge, TN 37830

M. T. Robinson

Oak Ridge National Laboratory P.0. Box X

Oak Ridge, TN 37830

A. F. Rowcliffe

Oak Ridge National Laboratory

P.0. Box $X$

Oak Ridge, TN 37830

C. Z. Serpan, Jr.

U.S. Naval Research Laboratory Washington, DC 20390

F. A. Smidt

U.S. Naval Research Laboratory

Washington, DC 20390

J. Moteff

University of Cincinnati

Cincinnati, $\mathrm{OH} 45221$

W. G. Wolfer

University of Wiscons in

Madison, WI 53706 
No. of

Copies

J. A. Spitznagel

Westinghouse Research and Development Center

1310 Beulah Rd.

Pittsburgh, PA 15235

ONSITE

DOE Richland Operations Office

W. A. Burns

5 Hanford Engineering Development Laboratory

T. K. Bierlein

D. G. Doran

M. Korenko

J. J. Laidler

H. H. Yoshikawa

25 Battelle-Northwest

T. W. Ambrose

E. R. Bradley

J. L. Brimhall

L. A. Charlot

T. D. Chikalla

S. D. Dahlgren

D. A. Dingee

J. W. Finnigan

W. G. Glass

J. Hartman

R. H. Jones

A. B. Johnson, Jr.

H. E. Kissinger

R. P. Marsha11

M. D. Merz

R. D. Nelson

L. C. Schmid

E. P. Simonen

M. T. Thomas

R. Wang

Technical Information (5) 